it. We can only mention here the very interesting sketch given by M. Nathorst of the relations of the Japanese flora to those of different parts of the Pacific basin; the paper ought to be translated in full in some language more familiar to the geologists of Western Europe. The memoir contains the description of seventy species of plants from Mogi, seven species from the coal-measures of Takasima, and seven species from the plants in the Berlin Museum. The descriptions are accompanied by sixteen plates.

Two other important papers, both in English, are contributed to the same volume by M. Otto Petterson. One of them embodies a general discussion, an account of which appeared in NATURE, vol. xxviii. p. 4I7, on the properties of water and ice between $-20^{\circ}$ to $+15^{\circ}$ Cels., on the ground of the author's own measurements. The second paper, "Contributions to the hydrography of the Siberian Sea," not only contains valuable information gathered from the very numerous measurements of depth, saltness, and temperature of water during Nordenskjöld's expeditions on the Kara Sea and along the Siberian coast, but also gives a most valuable sketch of the hydrography of the Kara Sea. It seemed that nothing new could be written on this northern Mediterranean Sea after the beautiful researches by Dr. Pettermann based upon the recent researches of the Norwegian seal-hunters. Still Mr. Petterson introduces a new element into the discussion, namely, the influence of the warm water poured into its basin by the Siberian rivers. During the summer the Kara Sea north of the Obi and Yenisei is covered with a layer of almost fresh water which has a depth of nearly twenty metres in the south, and a temperature of $6^{\circ}$ to $9^{\circ}$ Celsius in the summer. This layer thins out and becomes cooler as it advances towards the north, but still it reaches the north-eastern extremity of Novaya Zemlya, where it meets with the salt oceanic current brought along the western coast of the island. On the other hand, the middle parts of the Kara Sea are invaded by the Arctic current bringing cold and much salter water from the north-east. It passes underneath the fresh-water current and reaches the surface about the middle of the Kara Sea, where a saltness of 3.03 has been observed. This cold current, which has in the deepest parts of the Kara Sea (IOo to 222 metres) a temperature slightly oscillating betneen $-1^{\circ} 4$ to $-2^{\circ} \mathrm{O}$, and a saltness of 3.19 to 3.49 , is heated more or less on its surface, which reaches in the summer from $2^{\circ}$ to $4^{\circ}$ above zero in the south-western and northeastern parts of the Kara Sea : whilst in the middle, even on the surface, the temperature is generally about zero, or even $-0^{\circ} \cdot 8$. This distribution of currents explains the very slow melting of ice in the middle parts of the Kara Sea, which Dr. Pettermann compared to an ice-shoal floating in the middle on the surface of our ponds after a free channel has been opened along its coasts. Two maps on a large scale, showing the distribution of temperature and saltness in the Siberian Sea from Novaya Zemlya to Behring Strait, and embodying the results of Nordenskjöld's determinations of latitudes and longitudes on the Siberian coast, accompany the papers of $M$. Petterson.

We find in the same volume an elaborate paper, by A. Wirén, on the Chrtopods of the Siberian and Behring Seas. Six tables accompany this paper, which contains the description of seventy-three species of Chætopods. The chief features of this fauna already being known from Nordenskjold's preliminary report, we only notice that the richest part of the Siberian Sea is the Kara Sea, where the Veya Expedition and those of 1875 and 1876 discovered no less than sixty-nine species, whilst in the remainder of the Siberian Sea only fifty-three species were found until now.

Finally, we notice in the same volume M. Aug. Wijkander's paper on the magnetic observations made during the expedition (in French), and an appendix to the paper on the geographical determinations, by $A$. Lindhagen. It appears from the former that the mag. netic declination on the coast of North-Eastern Asia presents several anomalies. The position of the isodynams is quite different from those given on the map of the German Admiralty ("Isodynamen und Werthe des magnetischen Potentials für I 880 "). As to the inclination, it is but slightly different from the values which would result from Sabine's work; but the declination differs notably from the values given on the maps both of the German and English Admiralties. For the Behring Strait region this last, however, is decidedly the best, the average corrections for the English map being $-2^{\circ} \cdot 1$, and $-3^{\circ} \cdot 7$ for the German Admiralty map. The errors result from the secular variation having been only calculated, and not yet measured directiy.

The interest awakened by the expedition of the Vega towards the North Siberian Sea will be perpetuated by this work. The serious scientific spirit in which the different departments of natural history are dealt with in the records of the cruise of the Vega will contribute more towards the increase of our knowledge of the Arctic regions than many costlier expeditions.

The third volume, just published, is mostly occupied by F. Kjellmann's "Algæ of the Arctic Ocean" (430 pages, with 3 I plates). This work-the result of the author's ten years' Arctic experience-not only contains a complete botanical description of all the Algæ of the Arctic Ocean which came under notice; the author gives also a general sketch of the Arctic marine flora, with its subregions; he discusses the causes which gave it its present character: structure of the coast-line, tides, characters of the bottoin, temperature, and so on; and he endeavours to draw also the chief lines of its evolution, giving thus rich material for solid generalisations.

Mr. W. Leche cont:ibutes to the same volume a note on the forty-two species of Lamellibranchiata brought in by the Vega; Mr. P. T. Cleve describes (in English) the Diatoms collected in the Arctic Ocean and on the return journey of the expedition, his paper being illustrated by five plates, which figure eighty-four species, mostly new and Prof. P. Kramer and Dr. C. J. Neuman describe (in German) thirteen new species of Acarids. $\quad$ P. K.

\section{EARTH TREMORS}

$\mathrm{O}^{\mathrm{F}}$

$F$ the various movements to which the crust of the earth is subject, the minute motions called earth tremors attract our attention by their universality. Between them and the other motions which affect the soil the difference is chiefly in degree.

Eartbquakes are the sudden and violent movements of the ground. Earth pulsations, which may be observed as terminal phenomena of large earthquakes, are movements of considerable amplitude, but so slow in period that without the aid of instruments they may be passed by unnoticed. Earth oscillations are the secular movements of upheaval and depression evidenced to us by raised beaches, sunken forests, and other geological phenomena. Lastly, we have earth tremors, or movements quick in period, but which escape our attention on account of the smallness in their amplitude. As these latter are phenomena whic's are probably observable in all portions of the globe, and have as yet attracted but little attention, excepting perhaps where they have proved themselves troublesome intruders affecting astronomical and other observations of a delicate nature, I purpose giving an epitome of the more important results which their observation has yielded.

Earth tremors produced by artificial disturbances, such as the passing of carriages or trains, the movements of machinery or bodies of people, are at our disposal for 
daily observation. At Greenwich Observatory the tremulous motion in the soil, especially noticeable on bank holidays and at times when Greenwich Park was unustually crowded, resulted in the construction of an apparatus in which the dish of mercury used in the determination of the collimation error of the transit circle was suspended by flaccid springs. By means of this contrivance the tremulous motions of the ground were absorbed before they reached the mercury, and the difficulty of observation was overcome. French engineers, working with delicate surveying instruments in crowded cities, have similarly been compelled to suspend a portion of their apparatus, so that a steady image could be obtained. Prof. H. M. Paul, seeking for a site for the Naval Observatory at Washington, found that the image of a star reflected from a tray of mercury was disturbed by a train passing at the distance of a mile. Lieut.-Col. Palmer, when engaged in observing the transit of Venus in New Zealand, discovered that a ditch a few feet in depth was sufficient to intrench his instruments against the disturbance created by trains passing at a distance of 700 yards. Capt. Denman found the effect of a goods train to be transmitted I Ioo feet over marshy ground, but vertically above the train, passing through a tunnel in sandstone, the disturbance extended only roo feet. One result obtained from these and numerous other observations upon artificially produced tremors indicates that these disturbances are superficial, and although they may creep up the surface of a gently sloping hill, their spread is checked by a steep cutting.

Naturally produced tremors differ from those just spoken of by the fact that their distribution is not so superficial, and not only are they to be observed in the most substantial structures which engineers can design, but they are to be equally well seen in cellars and in the walls of rocky caves. Some knowledge of the depth to which they extend might be obtained by a few microseismic observations in the deep mines of Lancashire and other parts of the United Kingdom. As the observations are so simple, and the instrument required so easily constructed-in fact, it may be home made-it is earnestly desired that some of our mine managers will spontaneously undertake this work.

I make this suggestion, not only on account of the scientific value of the work, but because there are reasons to believe that such observations may lead to results of a practical value by relations they may hold to the escape of gas, the circulation of subterranean waters, and other underground phenomena. The instrument I should recommend for this purpose is the tromometer of Bertelli and Rossi. This is shown in the accompanying figure. $B$ is the bob of a pendulum about roo grammes in weight, suspended by a very fine wire about $\mathrm{I} \frac{1}{2}$ metres in length. The whole is inclosed in a tube. The style $S$ of this pendulum is seen reflected by the prism $P$ by means of the microscope $M$. The eye-piece $E$ of this microscope con tains a micrometer scale, by which to measure the amplitude of the motion of the style.

The direction of motion may be obtained by turning the eye-piece until the scale is parallel with the direction of motion, and this direction then read off from the position of an index moving over compass divisions marked on the fixed tube of the microscope. To commence with, the style of a pendulum might be looked at directly with a microscope, or two microscopes placed at right angles, having magnifications of forty or fifty diameters; and if it was found that movements existed, the prism and micrometer scale might be added subsequently. The pendulums may be hung from spikes driven in the solid rock or from an iron stand.

The chief results which have been obtained with instruments of this type are those which have been arrived at in Italy. The father of the science of microseismology is Father Bertelli of Florence, who, since I 870 , has made many thousands of observations under a variety of circumstances. Another ardent worker at this subject is Prof. M. S. de Rossi at Rome, by whose exertions numerous observatories have been established throughout the whole of Italy where these observations are systematically carried on. In making these observations every precaution appears to have been taken to avoid accidental disturbances, and the experiments have been repeated in a variety of forms. The results which from time to time have been announced are of the greatest interest to those who study the "physics of the earth's crust," and appear to be leading not only to the establishment of laws of scientific value, but also to the elucidation of phenomena which have an intimate connection with our every-day existence.

It would seem that the soil of Italy is in incessant movement, there being periods of excessive activity usually lasting about ten days. Such a period may be called a seismic storm. These storms are separated by periods of relative calms. The storm; have their greater regularity

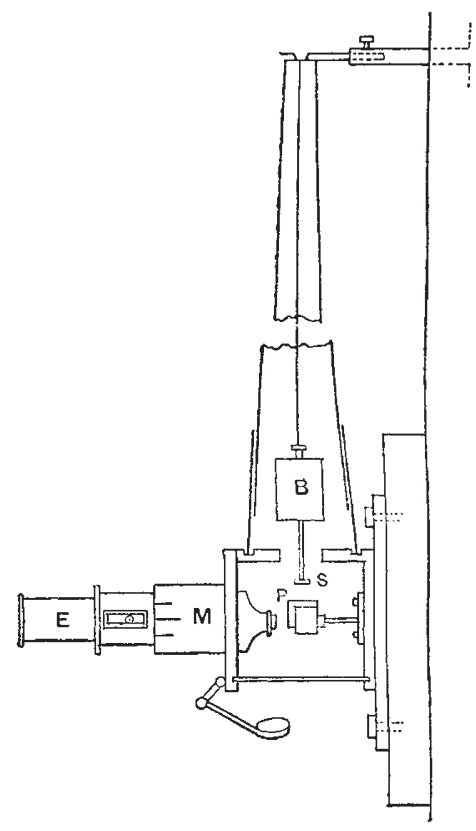

in winter, and sharp maximums are to be observed in spring and autumn. In the midst of such a period, or at its end, there is usually an earthquake. Usually these storms are closely related to barometric depressions. To distinguish these movements from those which occur under high pressure, they are called baro-seismic movements, the latter being called volcano-seismic movements. The relation of these storms to barometric fluctuation has been observed to be very marked during the time of a volcanic eruption. At the commencement of a storm the motions are usually small, and one storm lasting two or three days may be joined to another storm. In such a case the action may be a local one. It has been observed that a barometrical depression tended to bring a storm to a maximum, whilst an increase of pressure would cause it to disappear. Sometimes these actions are purely local, but at other times they may affect a considerable tract of land.

If a number of pendulums of different lengths are observed at the same place, there is a general similarity in their movements, but it is also evident that the free period of the pendulum more or less disturbs the character of the record. The greatest amplitude of motion in a set of pendulums is not reached simultaneously by all the 
pendulums, and at every disturbance the movement of one will predominate. From this Rossi argues that the character of the microseismical motions is not constant.

Bertelli observed that the direction of oscillation of the pendulums is different at different places, but each place will have its particular direction dependent upon the direction of valleys and chains of mountains in the neighbourhood. Rossi shows that the directions of movement are perpendicular to the direction of lines of faults, the lips of these fractures rising and falling, and producing two sets of waves, one set parallel to the line of fracture and the other perpendicular to such a direction. These movements, according to Bertelli, have no connection with the wind, rain, change of temperature, and atmospheric electricity.

The disturbances, as recorded at different towns, are not always strictly synchronous, but succeed each other at short intervals. If, however, we take monthly curves of the disturbances as recorded at different towns in Italy, we see that these are similar in character. The maximum disturbances occur about the winter solstice and the ninimum about the summer solstice, and in this respert they show a perfect accordance with the curves drawn by Mallet to show the periodicity of earthquakes.

At Florence before a period of earthquakes there is an increase in the amplitude and frequency of vertical movements. The vertical movements do not appear to come in with the horizontal barometrical disturbances, but they appear to be connected with the seismic disturbances. They are usually accompanied with noises in the telephone, but as the microphone is so constructed a:s to be more sensitive to vertical motion than to horizontal motion, this is to be expected. This vertical motion would appear to be a local action, inasmuch as the accompanying motions of an earthquake which originates at a distance are horizontal. Storms of microseismical motions appear to travel from point to point. Sometimes a local earth. quake is not noticed on the tromometer, whilst one which occurs at a distance, although it may be small, is distinctly observed. To explain this, Bertelli suggests the existence of points of interference and the existence of nodes.

Similar results were arrived at by Rossi when experimenting at different points on the sides of Vesuvius. Galli noticed an augmentation in microseismic activity when the sun and moon are near the meridian. Grablovitz found from Bertelli's observations a maximum two or three days before the syzigies, and minimum three days after these periods. He also found that the principal large disturbances occurred in the middle of periods separating the quadrature from the syzigies, the apogee from perigee, and the solstice period from the nodes, whilst the smallest disturbances happened in the middle of periods opposed to these.

P. C. Melzi says that the curves of microseismical motions, earthquakes, lunar and solar motions, show a concordance with each other. With the microphone Rossi hears sounds which he describes as roarings, explosions, occurring isolated or in volleys, metallic and bell-like sounds, ticking, \&c., which he says revealed nitural telluric phenomena. Tlese are sometimes intolerably loud. At Vesuvius the vertical shocks corresponded with a sound like volleys of musketry, whilst the undulating shocks gave the roaring. Some of these sounds could be imitated artificially by rubbing together the conducting-wires in the same manner in which the rocks must rub against each other at the time of an earthquake, or by placing the microphone on a vessel of boiling water, or by putting it on a marble slab and scratching and tapping the under side of it.

These then are some of the more important results which have been arrived at by the study of microseismic motions. One point which seems worthy of attention is that they appear to be more law-abiding than their violent relations, the earthquakes, and as phenomena in which natural laws are to be traced they are certainly deserving of our attention. As to whether they will ever become the means of forewarning us against earthquakes is yet problematical. Their systematic study, however, will enable us to trace the progress of a microseismic storm from point to point, and it is not impossible that we may yet be enabled to foretell where the storm may reach its climax as an earthquake. This, I believe, is a view held by Prof. de Rossi.

Before the earthquake of San Remo, on December 6 , 1874, Rossi's trcmometer was in a state of agitation, and similar disturbances were observed at Livorno, Florence, and Bologna. Since February, 1883, I have observed a tromometer in Japan, and such results as have been obtained accord with results obtained in Italy.

The increase in microseismical activity with a fall of the barometer is very marked. The style of the pendulum does not always oscillate about the same point-there is a deflection in the vertical. In Manila Father Faura also makes observations with a tromometer, which I am told gives him by movements very decided indications of approaching typhoons.

As to the cause of tromometric movements we have a field for speculation. Possibly they may be due to slight vibratory motions produced in the soil by the bending and crackling of rocks produced by their rise upon the relief of atmospheric pressure. If this were so, we should expect similar movements to be produced at the time of an increase of pressure.

Rossi suggests that they may be the result of an increased escape of vapour from molten materials beneath the crust of the earth consequent upon a relief of external pressure. The similarity of some of the sounds which are heard with the microphone to those produced by boiling water are suggestive of this, and Rossi quotes instances when underground noises like those which we should expect to hear from a boiling fluid have been heard before earthquakes without the aid of microphones. One instance was that of Viduare, a prisoner in Lima, who, two days before the shock, 1824 , repeatedly predicted the same in consequence of the noises he heard.

A possible cause of disturbances of this order may be the sudden fluctuations in barometric pressure which are visible during a storm.

In addition to the observations which have been especially made for the purpose of recording earth tremors, there are numerous observations which have been made upon these disturbances when they have appeared as intruders in investigations on other subjects. Amongst these may be mentioned the endeavours to measure changes in the vertical, as for instance those which might be produced by the attractive influence of the moon.

Prof. Zöllner, who invented the horizontal pendulum, found that the readings of his instrument were always changing.

M. d'Abbadie, who for several years observed a reflected image in a pool of mercury contained in a basin of solid rock, found it a rare occurrence that the surface of the mercury was tranquil. Sometimes it appeared to be in violent motion.

George and Horace Darwin, in their experiments at Cambridge to determine the disturbing influence of gravity by lunar attraction, found that the irregular and persistent tremors in the ground, as indicated by the instruments, were sufficient to mask whatever effects may have been due to the influence of the moon.

A full account of these latter observations is to be found in Messrs. G. and H. Darwin's Report for 1882 to the British Association.

The general conclusion, then, is that from observations in England, France, Germany, Italy, the Philippines, 
Japan, and, I may add, the West Indies, it would appear that the crust of the globe is practically in a constant state of tremor. The variations in these movements are more law-abiding than the large earth movements, and they show a direct relationship to barometric fluctuation.

Their relationship to many other telluric and atmospheric phenomena, together with their cause, has yet to be discovered. As every one has the opportunity to observe these phenomena, they call for attention. Just as a turbulent sea outraces a coming typhoon and gives mariners warning of approaching danger, it is possible that these microscopic disturbances of the soil may hold connection with subsequent phenomena, and lead us by their study to the better understanding of the complexity of phenomena with which we are surrounded.

Tokio, Japan

JOHN MILNE

\section{THE MECHANICAL THEORY OF MAGNETISM}

J $F$ Prof. Hughes were as great a master of writing English as he is of experimenting, his views on magnetism would receive speedier acceptation, for they would then probably be understood without that close study which his involved sentences and heterogeneous paragraphs now demand. It is very remarkable that such an ardent worker, such a deep thinker, and such a clear and simple experimenter should have such difficulty in expounding his views on paper. His experimental demonstrations are always clear and convincing, his recent lecture at the Royal Institution appealed to every degree of intelligence present, but his papers at the Royal Society want some strong external directing influence to render their meaning evident.

What is magnetism, according to this expert philosopher? It is an inherent quality of the molecules of matter, as determined and constant as that of their gravity, affinity, or cohesion, and like these qualities it differs in degree with every kind of matter. He does not attempt at present to define it closer than this. We cannot tel what gravity is, neither need we say what magnetism is. All Prof. Hughes says is that every molecule in nature is a little magnet imbued with a certain polarity varying in degree but constant for each substance, in virtue of which it has a north and a south pole along the same axis, and that the only change that takes place is a change in the direction of this polar axis. When these molecules are symmetrically arranged by some external directing influence, so that all their poles lie in the same direction, we have evident magnetism. Iron becomes a magnet in virtue of the fact that its molecules are free to move under the influence of external magnetic action, while copper is not a magnet because its molecules are immovable and irresponsive to the same cause. Steel becomes permanently magnetised because its molecules are rigid, and retain the axial direction impressed upon them. Soft iron is readily demagnetised because its molecules have great freedom of motion. Coercive force is therefore simply absence of freedom of molecular motion-it is, indeed, molecular rigidity. The extent to which the axis of polarity can be deflected from its normal direction is its point of saturation.

Evident magnetism is the symmetrical arrangement of the polarised molecules along one line; neutrality is symmetrical arrangement of the same molecules in closed curves. In both cases the sum of the magnetic influence of all the molecules is the same; but in evident magnetism it is directed outwards, in neutrality it is directed inwards. Remaining magnetism is partial neutrality. The experimental way in which Prof. Hughes demonstrated these conclusions is the most beautiful investigation he has yet made. He proves the existence of the same polarity in the atmosphere and in the ether, and he attributes diamagnetic effects to the higher magnetic capacity of the ether than of the substances suspended in it. It is therefore a differen- tial action. Molecules, moreover, have inertia-they resist being put in motion; and when in motion they resist stoppage-they possess momentum. The direction of the axis of polarity can be displaced by the physical fcrces, such as mechanical stress, heat, or electricity. He shows that mechanical motion, heat, and electricity are of similar kind-they are vibratory, or some mode of motion. Magnetism, however, he considers not to be a mode of motion, and therefore it is not a physical force. It is simply an arrangement of the molecules of matter in symmetry or dissymmetry under the influence of some physical force. He seems to imply, though he does not directly say so, that the influence of electric currents upon magnets is not due to any direct action between them, but to the fact that the currents have polarised the ether in which both are suspended.

His views are very broad and highly suggestive, but there are some points that are not clear and that demand further elucidation. Why, for instance, does mechanical elongation and contraction take place when bars of iron are magnetised and demagnetised ? How can heat and strong sonorous vibrations be produced unless there be a considerable expenditure of energy? How does he account for the attractive and repulsive properties of magnets, and for magnetic induction? He has certainly wrested magnetism from the realms of hypothesis and brought it within the domain of theory. The days of Coulomb and Poisson's fluids and Ampère's elementary currents of electricity are over; the molecular character of magnetism is experimentally established; but what is a molecule, and how becomes it polarised unless it be in rotation? How does the external directing influence act? We are also inclined to ask, Has Prof. Hughes sufficiently grasped Ampère's theory? It was purely mathematical, based on the assumption of the circulation of currents around each molecule. He goes no further than Ampere did, for he has not answered the question, What is polarity? In fact his polarised molecules are all little magnets, and no theory of magnetism will be complete until it explains these little magnets. Thus the difference between Ampere and Hughes is the difference between a current and a magnet.

However, on the assumption that a molecule is a magnet, Prof. Hughes has built up a very complete theory, which he has demonstrated experimentally in a way that places him in the very front rank of experimental philosophers.

\section{NOTES}

THE number of candidates up this session for the Fellowship of the Royal Society is sixty-seven.

WE understand that Sir Joseph Hooker has been nominated one of the vice-presidents for the Montreal meeting of the British Association. Instead of Mr. Crookes, Prof. W. G. Adams will give one of the public lectures. For the reduction of the fares of members the sum of 14,000 dollars has been allotted, only tho e elected at or before the Southampton meeting being entitled to share in the subsidy. This is in addition to the liberal reductions that will be made by the steamship and railway companies. All the American railways will reduce their fares by one-haif. The American Association, which meets at Philadelpbia on September 3, has given a cordial invitation to the Montreal vis tors to take part in its meetings and excursions. Those wishing to share in the subsidy of 14,000 dollars must apply before September 25. For the Aberdeen meeting in 1885 , Sir I.yon Playfair will be proposed as president. A well-attended meeting of the Organising Committee of the Chemical Section has been held under the presidency of Prof. Roscoe. Promises of papers were received from several well-known chemists, and a small executive committee was formed to draw up a list of papers and to communicate with Canadian and American 